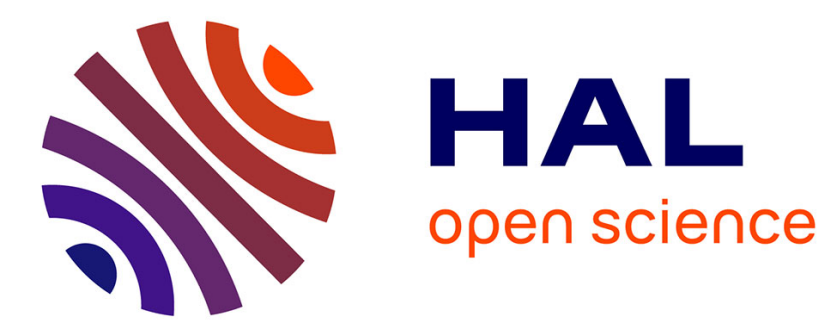

\title{
Disappearing conglomerates, assessment of the threat
}

\author{
Marine Hoquante, Morgane Sanselme, Ivo Rietveld, Gérard Coquerel
}

\section{To cite this version:}

Marine Hoquante, Morgane Sanselme, Ivo Rietveld, Gérard Coquerel. Disappearing conglomerates, assessment of the threat. Crystal Growth \& Design, 2019, 19 (12), pp.7396-7401. 10.1021/acs.cgd.9b01316 . hal-02336086

\section{HAL Id: hal-02336086 \\ https://hal.science/hal-02336086}

Submitted on 28 Oct 2019

HAL is a multi-disciplinary open access archive for the deposit and dissemination of scientific research documents, whether they are published or not. The documents may come from teaching and research institutions in France or abroad, or from public or private research centers.
L'archive ouverte pluridisciplinaire HAL, est destinée au dépôt et à la diffusion de documents scientifiques de niveau recherche, publiés ou non, émanant des établissements d'enseignement et de recherche français ou étrangers, des laboratoires publics ou privés. 


\title{
Disappearing conglomerates, assessment of the
}

\author{
threat
}

\author{
Marine Hoquante, $\uparrow$ Morgane Sanselme, $†$ Ivo B. Rietveld, $\uparrow$ Gérard Coquerel $\uparrow *$ \\ † Normandie Université, Laboratoire SMS-EA3233, Université de Rouen Normandie, F76821, \\ Mont Saint Aignan, France
}

† Université Paris Descartes, Faculté de Pharmacie, 4, av. de l'observatoire, 75006, Paris, France

\begin{abstract}
A racemic compound has been identified for the system: $(+)-(-)$ BINOL-OBn despite having been reported as a conglomerate. This heterochiral phase appears to be more stable than the conglomerate irrespective of the temperature. Its melting point exceeds by $20^{\circ} \mathrm{C}$ that of the racemic eutectic. In conjunction with the revised phase diagram, the crystal structures of the racemic compound and of the pure enantiomer have been compared. In the structure of the racemic compound $\left(Z^{\prime}=3\right)$ hydrogen bonds can be found whereas in the structure of the pure enantiomer $\left(Z^{\prime}=1\right)$ only $\pi-\pi$ and Van der Waals interactions are observed. The likelihood that a more stable racemic compound appears when processing a conglomerate (e.g. in preferential crystallization) is discussed.
\end{abstract}




\section{INTRODUCTION}

Biological systems demonstrate predominantly one-handedness. For the pharmaceutical industry, it means that the biological properties in a pair of enantiomers can be very different ${ }^{1,2}$. Accordingly, chiral separation is an important field of research. There are several approaches to access pure chiral molecules, such as: stereoselective synthesis, chromatography, biocatalytic synthesis and crystallization. Among the latter, deracemization is a promising resolution method at an industrial scale, because it leads to quantitative recovery of the starting racemic substrate as a single enantiomer ${ }^{1-4}$. It combines crystallization of a conglomerate forming system with simultaneous in situ racemization in the liquid phase ${ }^{5,6}$. The main limitation of this process is that it only applies to conglomerate forming systems, i.e. $5-10 \%$ of the racemic crystals ${ }^{7,8}$. Since racemization in the liquid is a requirement for the deracemization process, auxiliary racemizing agents are often needed ${ }^{9-11}$. In this work, we focused on conglomerates with enantiomers that are able to interconvert in solution under UV irradiation without any additional racemizing agent. A photoracemizable conglomerate forming system is required to prove the concept of photoderacemization.

1-1'-Binaphtyls ${ }^{12}$ and particularly 1-1'-Bi-2-naphtol (BINOL) and some of its derivatives are known to photoracemize in solution ${ }^{13,14}$. In 2016 Maria et al ${ }^{15}$ reported the crystal structure of 2'benzyloxy-1-1'-binaphtalene-2-ol (BINOL-OBn, Figure 1) and investigated the phase diagram of binary enantiomer mixtures. The system crystallizes in a $\mathrm{P} 2{ }_{1} 2_{1} 2_{1}$ space group (refcode UBULUB, CCDC 1443741) meeting the crystallographic requirement to reach homochirality in a deracemization process. Previously, Takahashi et al. reported the melting points of the pure enantiomer and of the racemic mixture, respectively $122^{\circ} \mathrm{C}$ and $103^{\circ} \mathrm{C}$ implying the presence of a eutectic transition at the racemic composition ${ }^{16}$. Because of its conglomerate, which makes the 
system amenable for resolution by crystallization, BINOL-OBn seemed to be a good candidate for photoderacemization.

BINOL-OBn is an atropisomer, which means that it exhibits axial chirality. The rotation of the bond connecting the two naphthyl groups is inhibited because of the steric hindrance caused by the two oxygen groups so that two conformers can be identified and isolated.

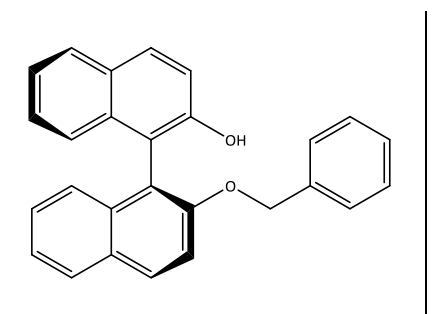

(S)-BINOL-OBn

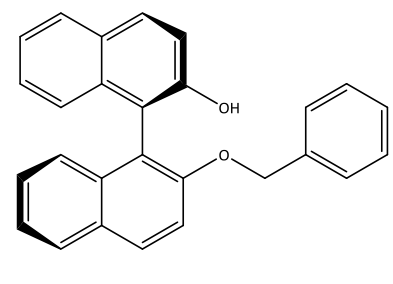

(R)-BINOL-OBn

Figure 1. Molecular structure of the two enantiomers of 2'-benzyloxy-1-1'-binaphtalene-2-ol

\section{RESULTS AND DISCUSSION}

\section{Preparation and characterization}

Pure $(R)$ enantiomer, $(S)$ enantiomer and racemic BINOL-OBn were synthesized according to a previously reported procedure ${ }^{17}$. The synthesis of racemic BINOL-OBn first gave rise to a viscous oil and the crystallization was not straightforward despite the absence of an apparent purity problem. However, after a month at room temperature, a stable racemic compound appeared. This new racemic compound was characterized by means of Differential Scanning Calorimetry (DSC), Infrared spectroscopy (IR), X-Ray powder diffraction (XRPD), Second Harmonic Generation (SHG) and single crystal X-ray diffraction (SCXRD). 


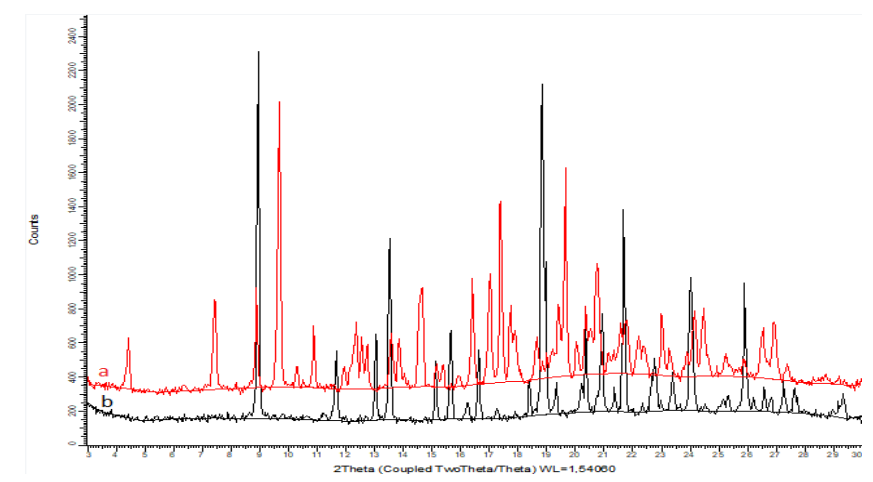

Figure 2. X-Ray powder diffraction patterns of a) racemic and b) enantiopure BINOL-OBn

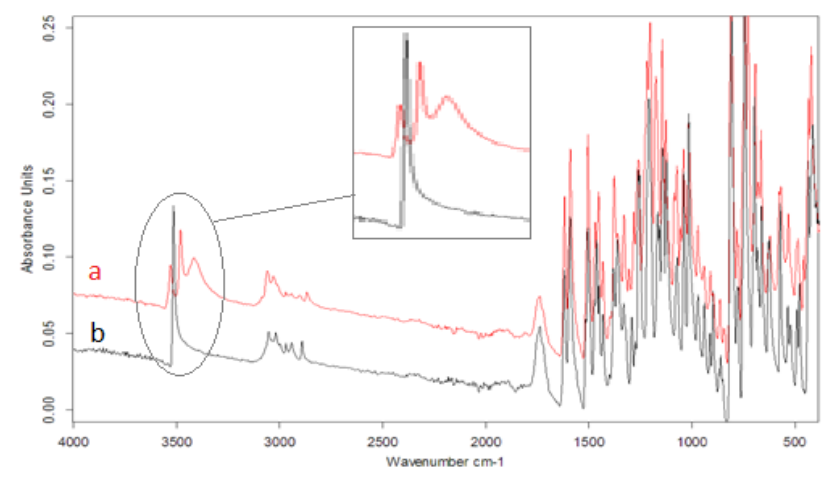

Figure 3. Infrared spectra of a) racemic and b) enantiopure BINOL-OBn

The XRPD patterns of the enantiopure and of the racemic crystals do clearly not overlap (Figure 2). Moreover, the infrared spectrum of the racemic compound (Figure 3) shows three bands for the $\mathrm{OH}$ stretching vibrations at $v_{\mathrm{OH}}=3413 \mathrm{~cm}^{-1}, v_{\mathrm{OH}}=3482 \mathrm{~cm}^{-1}$ and $v_{\mathrm{OH}}=3529 \mathrm{~cm}^{-}$ 1 implying that there are three hydroxyl groups with different interactions in the structure, whereas for the enantiopure structure a single $\mathrm{OH}$ stretching band exists at $v_{\mathrm{OH}}=3515 \mathrm{~cm}^{-1}$. The differences between the spectra and diffraction patterns prove the existence of two different phases of which the (rac)-BINOL-OBn has never been observed before. The centrosymmetry of the crystals was investigated by Second Harmonic Generation (SHG). SHG signal only occurs for crystals with non-centrosymmetric space groups and is therefore a fast method to recognize 
such type of systems ${ }^{20}$. While irradiating at $900 \mathrm{~nm}$, no SHG signal at $450 \mathrm{~nm}$ was observed confirming the heterochiral packing of this new phase.

\section{Constructing the binary phase diagram}

Considering the appearance of the racemic compound, the previously reported phase diagram needs to be revised. Pure enantiomer, racemic compound and their mixtures were analyzed by DSC (heating rate $=5 \mathrm{~K} / \mathrm{min}$ ). The data are available in the supplementary information. Mixtures with different enantiomeric compositions were prepared by manual grinding assisted by a small amount of solvent and the results are summarized in Table $\mathbf{1}$ and $\mathbf{2 .}$

Table 1: Temperature of solidus and liquidus for binary mixtures between the pure enantiomer and the racemic compound of BINOL-OBn

\begin{tabular}{|l|l|l|l|}
\hline $\mathrm{X}_{(R)-\text { BINOL-OBn }}$ & $\mathrm{T}_{\text {solidus }} / \mathrm{K}$ & $\mathrm{T}_{\text {liquidus }} / \mathrm{K}$ & $\begin{array}{l}\text { Enthaply of } \\
\text { fusion } / \mathrm{J}^{-1}\end{array}$ \\
\hline 1 & & $393.8^{\mathrm{a}}$ & $77 \pm 5^{\mathrm{a}}$ \\
\hline 0.919 & 380.2 & 391.2 & \\
\hline 0.872 & 381.4 & 388.1 & \\
\hline 0.791 & 381.6 & 386.0 & \\
\hline 0.752 & 382.1 & 382.4 & \\
\hline 0.656 & 382.1 & 386.9 & \\
\hline 0.57 & 383.1 & 388.4 & \\
\hline 0.5 & & $388.8^{\mathrm{a}}$ & $79 \pm 5^{\mathrm{a}}$ \\
\hline
\end{tabular}

\footnotetext{
${ }^{a}$ Results are the mean of $n=4$ experiments. Temperatures are given with an uncertainty of \pm $0.5 \mathrm{~K}$.
} 
Table 2. Temperature of solidus and liquidus for metastable binary mixtures between the pure enantiomers $(R)$ - and $(S)$-BINOL-OBn

\begin{tabular}{|l|l|l|l|}
\hline $\mathrm{X}_{(R) \text {-BINOL-OBn }}$ & $\mathrm{T}_{\text {solidus }} / \mathrm{K}$ & $\mathrm{T}_{\text {liquidus }} / \mathrm{K}$ & $\begin{array}{l}\text { Enthaply of } \\
\text { fusion } / \mathrm{J}^{-1}\end{array}$ \\
\hline 1 & & $393.8^{\mathrm{a}}$ & $76.9 \pm 5^{\mathrm{a}}$ \\
\hline 0.183 & 364.6 & 385.7 & \\
\hline 0.38 & 366.2 & 376.6 & \\
\hline 0.5 & 365.1 & & $72.7 \pm 5$ \\
\hline
\end{tabular}

\footnotetext{
${ }^{a}$ Results are the mean of $n=4$ experiments. Temperatures are given with an uncertainty of \pm $0.5 \mathrm{~K}$.
}

The liquidus of the racemic compound was calculated using its melting point $\left(115.6 \pm 0.5{ }^{\circ} \mathrm{C}\right)$

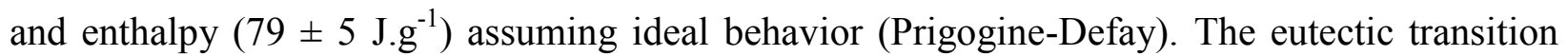
between the enantiomer and the racemic compound is obtained through the intersection of the two equations at $109 \pm 1{ }^{\circ} \mathrm{C}$ and it was experimentally found at $108.7 \pm 0.5^{\circ} \mathrm{C}$ indicating no significant deviation from ideality. The metastable eutectic liquid between the pure enantiomers corresponds to the racemic composition $\left(\mathrm{x}_{\text {metastable eutectic }}=0.5\right)$ with a melting temperature experimentally found at $92 \pm 0.5^{\circ} \mathrm{C}$, equal within error to the temperature obtained by the intersection of the Schröder equation $\left(\mathrm{T}_{\text {calculated eutectic }}=93 \pm 1^{\circ} \mathrm{C}\right)$ for the liquidus lines of the $\mathrm{R}$ and $\mathrm{S}$ enantiomers. The phase diagram for the BINOL-OBn system based on this fit and confirmed by experimental points, is shown in Figure 4. 


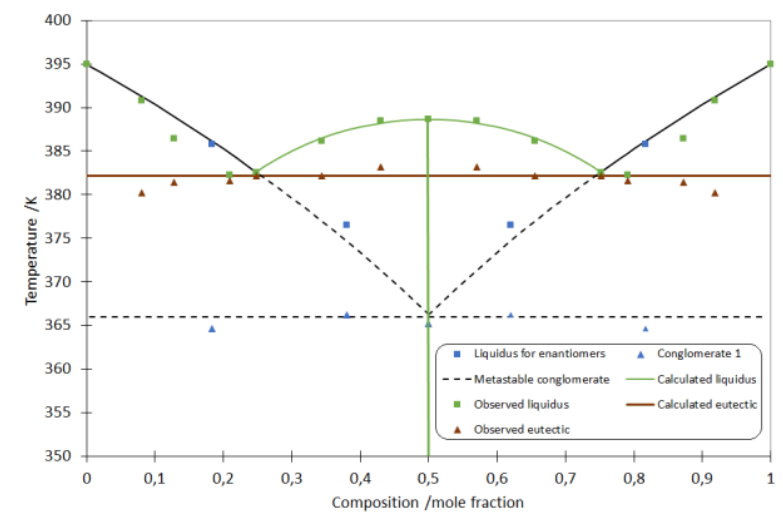

Figure 4. Binary phase diagram of BINOL-OBn based on the experimental data in Tables 1 and 2. The liquidus lines of the enantiomers are obtained by the Schröder equation and the liquidus line of the racemic compound has been calculated with the Prigogine-Defay equation. They have not been fitted to the liquidus points.

To test the stability of the conglomerate versus the racemic compound, 'artificial' conglomerate was prepared mixing powdered crystals of $(R)$ and $(S)$ enantiomers rigorously respecting the $<1-1>$ composition. A cross-seeding experiment was conducted at $-10^{\circ} \mathrm{C}$ in diethyl ether. After 48 hours, the diffractogram showed that the suspension was exclusively composed of the racemic compound indicating that it is the stable phase at $-10^{\circ} \mathrm{C}$ (Figure 5). Therefore BINOL-OBn is not amenable to resolution by crystallization under the given conditions.

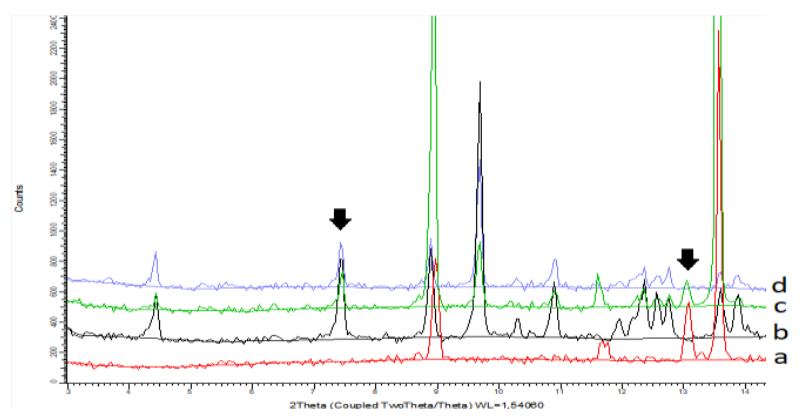

Figure 5. Diffractograms of a) (R)-BINOL-OBn, b) (rac)-BINOL-OBn, c) cross-seeding experiment after 6 hours, d) cross-seeding experiment after 48 hours. 
Taking into consideration the cross-seeding experiment and the fact that the racemic compound has a melting point of $115.6 \pm 0.5^{\circ} \mathrm{C}$ with a melting enthalpy of $79 \pm 5 \mathrm{~J} / \mathrm{g}$, whereas the eutectic temperature of the conglomerate is found at $92^{\circ} \mathrm{C}$ with a melting enthalpy of $73 \pm 5$ $\mathrm{J} / \mathrm{g}$, the racemic compound is clearly the more stable phase at room temperature. It is even likely that this stability is 'monotropic' in nature ${ }^{\mathrm{i}}$, considering that the melting enthalpy of the racemic compound appears to be $6 \mathrm{~J} / \mathrm{g}$ higher than that of the conglomerate. Nonetheless, strictly speaking the enthalpies have overlapping experimental errors, so a stable temperature domain for the conglomerate below $-10^{\circ} \mathrm{C}$ cannot entirely be excluded (through a eutectoid invariant).

It is surprising however, that the conglomerate has been observed in the first place and even by

two groups independently ${ }^{15,16}$, because the newly identified racemic compound melts more than 20 degrees higher than the racemic conglomerate and is the more stable form at room temperature. The complexity of the structure of the racemic compound with three molecules possessing different conformations in the asymmetric unit $\left(Z^{\prime}=3\right)$ might justify this behavior.

\section{Structural characterization and discussion}

Single crystals of ( $\mathrm{rac}$ )-BINOL-OBn were obtained by crystallization from chloroform/nhexane and the crystalline structure was resolved by single crystal X-ray diffraction.

\footnotetext{
${ }^{\mathrm{i}}$ strictly speaking this is not polymorphism since the following irreversible transformation $(\Delta \mathrm{G}<$ $0):<\mathrm{S}>+<\mathrm{R}>\rightarrow<\mathrm{RS}>$ involves three solid phases. Nevertheless, by analogy with a genuine monotropy we use that term.
} 
Table 3. Crystal data for ( $\mathrm{rac}$-BINOL-OBn compared to the pure enantiomer

\begin{tabular}{|c|c|c|}
\hline & (rac)-BINOL-OBn & $(S)$-BINOL-OBn ${ }^{15}$ \\
\hline CCDC Ref code & 1949382 & 1443741 \\
\hline Molecular Weight / g.mol ${ }^{-1}$ & 376.4 & 376.4 \\
\hline Crystal System & Monoclinic & Orthorhombic \\
\hline Space Group & $\mathrm{P} 2_{1} / \mathrm{n}$ & $\mathrm{P} 2{ }_{1} 2_{1} 2_{1}$ \\
\hline Z, Z & 12,3 & 4,1 \\
\hline $\mathrm{a} / \AA$ & $10.2821(7)$ & $8.4850(3)$ \\
\hline $\mathrm{b} / \AA$ & $40.035(3)$ & $11.3174(3)$ \\
\hline$c / \AA$ & $14.808(1)$ & $20.5379(7)$ \\
\hline$\beta / \circ$ & $92.216(2)$ & \\
\hline$V / \AA^{3}$ & $6091.0(7)$ & $1972.22(12)$ \\
\hline $\mathrm{d}_{\text {calc }} / \mathrm{g} \cdot \mathrm{cm}^{-3}$ & 1.231 & 1.264 \\
\hline$F(000) / e^{-}$ & 2376 & 788 \\
\hline Absorption coefficient $\mu\left(\mathrm{MoK} \alpha_{1}\right) / \mathrm{mm}^{-1}$ & 0.076 & 0.079 \\
\hline Temperature / K & 293 & $293 \pm 2$ \\
\hline
\end{tabular}

As shown in the crystallographic data collected in Table 3, in the crystal lattice of the racemic compound, three independent molecules with different conformations can be found in the asymmetric unit (see Figure 6) as inferred from the infrared spectrum (Figure 3). When considering the energies of isolated molecules in vacuum, one of the conformations displays a higher energy than the others (about 1.3 times higher for so-called MolA represented in yellow in Figure 6). The other two conformations ( $\mathrm{MolO}$ and $\mathrm{MolB}$ ) form dimers together through hydrogen bonds (Figure 7). These dimers exhibit $\pi-\pi$ interactions with adjacent dimers along the $\mathrm{c}$ axis giving rise to periodic bond chains (PBCs) in this direction (Figure 8). The interaction 
between adjacent PBCs along the $\mathbf{b}$ and $\mathbf{a}$ axes is ensured by MolA through $\pi-\pi$ interactions. The packing diagram is shown in Figure 9.

Whereas the pure enantiomer structure contains only $\pi-\pi$ and Van der Waals interactions, the racemic compound exhibits hydrogen bonding too. The cost in energy required to put one third of the molecules in the conformation A and the global lower density seems balanced by the gain in stability created by hydrogen bonds. However, kinetically this new phase is not favored because of the lower probability for the molecules to occur in three different conformations during crystallization, which may in particular be difficult for conformation A. This could explain why a metastable conglomerate has been observed before the racemic compound. The belated crystallization of the racemic BINOL-OBn is reminiscent of the molecules discussed in the papers by Bernstein on disappearing polymorphs mostly involving molecules that can adopt different conformations (i.e. conformational freedom) $)^{19-21}$. This case shows that the lack of hydrogen bonds in the conglomerate and the flexibility of the molecule are telltale signs of the possible crystallization of a racemic compound. It is possible to anticipate such a threat by challenging the stability of the conglomerate phase implementing the following procedure:

(i) Introduce as many variations of crystallization as possible with oscillatory physical stimuli (temperature cycling, spells of ultrasounds, rubbing effects on the inner wall of the container, different solvents and supersaturation, etc.). (ii) Use different routes for the synthesis of the racemic mixture. Indeed, different impurity profiles could change the nucleation and crystal growth rates drastically. (iii) Seed with racemic compounds of related chiral molecules. (iv) Compute possible racemic compounds especially with common space groups (e.g. P2 $1 / \mathrm{c}$; P-1; $\mathrm{C} 2 / \mathrm{c}$ ) and with $\mathrm{Z}^{\prime}>1$ and different conformations and assess their energies versus the energy of 
the pure enantiomer. Above all, the time is essential here as a metastable form can be kinetically favored $^{22}$.

So far, the 'reappearing' conglomerate has not been observed. Considering its relative stability, it will not be easy to obtain it again, even if it has been demonstrated that it is possible to obtain and to work on a metastable phase once a more stable one has been observed ${ }^{23}$. To do so, the right experimental conditions must be found (e.g. a solvent or an impurity that inhibits the formation of nuclei of the stable form) ${ }^{24-26}$.

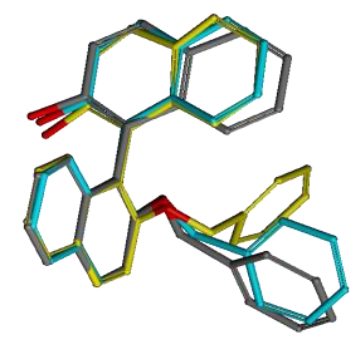

Figure 6. The three independent molecules in ( $\mathrm{rac}$ )-BINOL-OBn asymmetric unit (MolA in yellow, MolO in blue and MolB in grey)

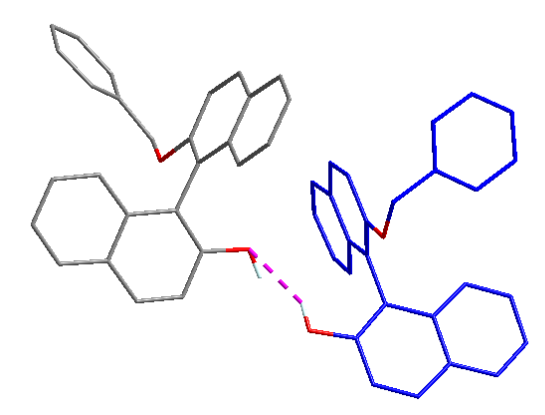

Figure 7. One dimer formed by the hydrogen-bond interaction (dashed pink line) between MolO (blue) and MolB (grey) 


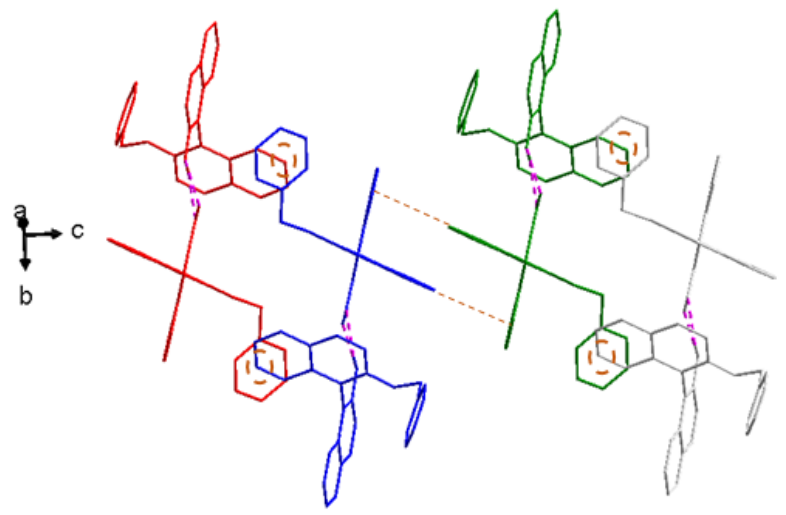

Figure 8. Consecutive dimers (red, blue, green and light grey) along c, establishing $\pi$ interactions (dashed red lines) at multiple points forming a PBC

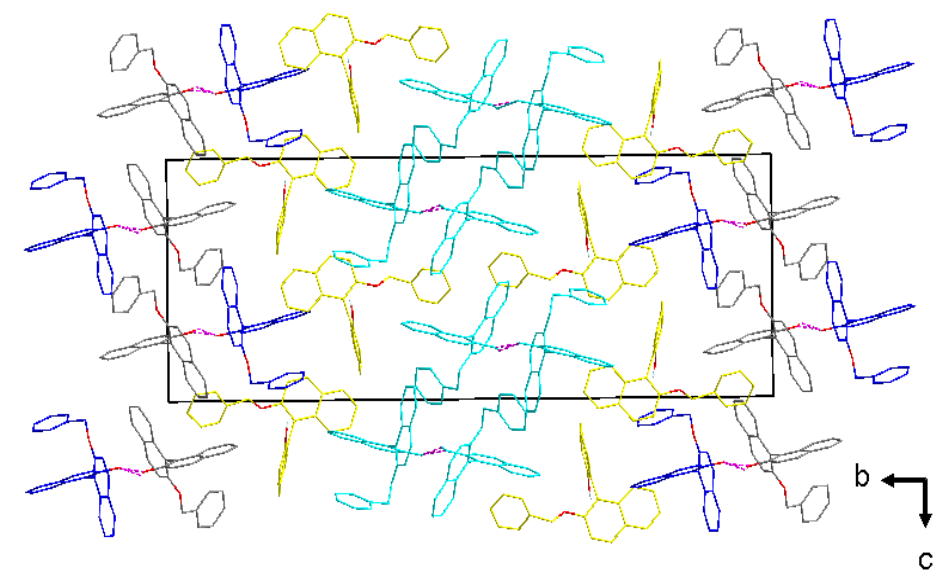

Figure 9. Projection along a of the cell packing diagram (one ribbon is displayed in light blue, in yellow MolA)

\section{CONCLUSION}

This work demonstrates that pure racemic BINOL-OBn should not be a suitable system for deracemization because, contrary to earlier reports, a racemic compound appears to be more stable than the conglomerate. The melting point of the racemic compound exceeds by $20^{\circ} \mathrm{C}$ the eutectic temperature of the conglomerate. However, there are possibilities to find another 
conglomerate with an appropriate solvent or coformer ${ }^{27}$. As with any crystallization process, it is difficult to predict such behavior and chemists should be aware of the possibility that a more stable form may appear. The risk may be more pronounced if the crystal structure mainly depends on Van der Waals interactions, whereas H-bond donors and acceptors are available in the molecule in particular when combined with molecular flexibility.

\section{EXPERIMENTAL}

$(R)$, $(S)$, and racemic Binol were acquired from Alfa Aesar. The conversion of 1-1'binaphtalene-2-ol to 2'-benzyloxy-1-1'-binaphtalene-2-ol was carried out in a one-step synthesis according to a previously reported procedure ${ }^{17}$ with a yield between 78 to $89 \%$ (up to $5 \mathrm{~g}$ ). The

${ }^{1} \mathrm{H}$ NMR data was in accordance with the literature. Details are shown in the supplementary material.

\section{Differential Scanning Calorimetry (DSC)}

DSC experiments were performed using a Netzsch DSC 214 Polyma apparatus on powder samples. Each DSC run was completed in aluminum pans with pierced lid and the atmosphere was regulated by a nitrogen flux $(40 \mathrm{~mL} / \mathrm{min})$. The Netzsch Thermal Analyses Proteus Software was used to treat the data. Onset temperatures were used as the melting points.

\section{X-Ray Powder Diffraction (XRPD)}

XRPD analyses were performed using a D8-Discover diffractometer from Bruker equipped with a $\theta / \theta$ goniometer. The incident $\mathrm{X}$-ray beam wavelength is monochromatic $\mathrm{Cu} \mathrm{K} \alpha$ radiation 
$\left(\lambda=1.5418 \AA\right.$ ). The diffraction patterns were recorded between 3 to $30^{\circ}$ by steps of $0.02^{\circ}$ with 0.5 second per step and 20 rotations of the sample holder per minutes. The EVA software of Bruker was used for the treatment of the data.

\section{Single Crystal X-Ray Diffraction (SCXRD)}

The crystal structure was determined by single crystal diffraction on a SMART APEX diffractometer (with Mo K $\alpha_{1}$ radiation: $\lambda=0.71073 \AA$ ). The cell parameters and the orientation matrix of the crystal were preliminary determined by using the SMART Software. Data integration and global cell refinement were performed with the SAINT Software. Intensities were corrected for Lorentz, polarization, decay and absorption effects (SAINT and SADABS

Software) and reduced to $\mathrm{FO}^{2}$. The program package WinGX3 was used for space group determination, structure solution and refinement.

\section{Second Harmonic Generation (SHG)}

SHG analysis was carried out with an Insight $\mathrm{X} 3$ single laser with automated dispersion compensation (Spectra- Physics) and a TCS SP8 MP confocal microscope (Leica Microsystems) at $900 \mathrm{~nm}$. The laser was controlled with the LASX Leica software.

InfraRed (IR)

Infrared spectra were obtained with an Alpha Platinum ATR spectrometer from Bruker. The program Opus was used for the data treatment. 


\section{Energy calculations}

The energies of the isolated molecules in vacuum were calculated with the software Material Studio using the Dreiding forcefield and the Gasteiger method to take into account the charge distribution over the molecules.

\section{ASSOCIATED CONTENT}

\section{Supplementary Information}

The following files are available free of charge.

Synthesis of 2'-benzyloxy-1-1'-binaphtalene-2-ol racemic, $R$ and $S$ enantiomer, ${ }^{1} \mathrm{H}$ NMR spectra, TG and DSC thermograms for the racemic compound, the pure enantiomer and enantiomeric mixtures (PDF).

Crystallographic data for the structures reported in this paper have been deposited at the Cambridge Crystallographic Data Center, CCDC 1949382

\section{AUTHOR INFORMATION}

\section{Corresponding Author}

*E-mail: gerard.coquerel@univ-rouen.fr

ORCID Marine Hoquante: 0000-0003-1242-7645

ORCID Ivo B. Rietveld: 0000-0001-5987-3998

ORCID Gerard Coquerel: 0000-0001-8977-8676 


\section{Funding Sources}

This research is part of a PhD thesis funded by the French ministry of research.

\section{REFERENCES}

(1) Viedma, C. Chiral Symmetry Breaking During Crystallization: Complete Chiral Purity Induced by Nonlinear Autocatalysis and Recycling. Phys. Rev. Lett. 2005, 94 (6), 065504. https://doi.org/10.1103/PhysRevLett.94.065504.

(2) Oketani, R.; Hoquante, M.; Brandel, C.; Cardinael, P.; Coquerel, G. Practical Role of Racemization Rates in Deracemization Kinetics and Process Productivities. Cryst. Growth Des. 2018, 18 (11), 6417-6420. https://doi.org/10.1021/acs.cgd.8b01263.

(3) Suwannasang, K.; Flood, A. E.; Rougeot, C.; Coquerel, G. Use of Programmed Damped Temperature Cycles for the Deracemization of a Racemic Suspension of a Conglomerate Forming System. Org. Process Res. Dev. 2017, $21 \quad$ (4), 623-630. https://doi.org/10.1021/acs.oprd.7b00028.

(4) Rougeot, C.; Guillen, F.; Plaquevent, J.-C.; Coquerel, G. Ultrasound-Enhanced Deracemization: Toward the Existence of Agonist Effects in the Interpretation of Spontaneous Symmetry Breaking. Cryst. Growth Des. 2015, $15 \quad$ (5), 2151-2155. https://doi.org/10.1021/cg501765g.

(5) Noorduin, W. L.; Vlieg, E.; Kellogg, R. M.; Kaptein, B. From Ostwald Ripening to Single Chirality. Angew. Chem. Int. Ed Engl. 2009, 48 (51), 9600-9606. https://doi.org/10.1002/anie.200905215. 
(6) Sögütoglu, L.-C.; Steendam, R. R. E.; Meekes, H.; Vlieg, E.; Rutjes, F. P. J. T. Viedma Ripening: A Reliable Crystallisation Method to Reach Single Chirality. Chem. Soc. Rev. 2015, 44 (19), 6723-6732. https://doi.org/10.1039/C5CS00196J.

(7) Jacques, J.; Collet, A.; Wilen, S. H. Enantiomers, Racemates and Resolutions; John Wiley \& Sons Inc: New York, 1981.

(8) Viedma, C.; Coquerel, G.; Cintas, P. 22 - Crystallization of Chiral Molecules. In Handbook of Crystal Growth (Second Edition); Nishinaga, T., Ed.; Elsevier: Boston, 2015; pp 951-1002. https://doi.org/10.1016/B978-0-444-56369-9.00022-8.

(9) Noorduin, W. L.; Bode, A. A. C.; Meijden, M. van der; Meekes, H.; Etteger, A. F. van; Enckevort, W. J. P. van; Christianen, P. C. M.; Kaptein, B.; Kellogg, R. M.; Rasing, T.; et al. Complete Chiral Symmetry Breaking of an Amino Acid Derivative Directed by Circularly Polarized Light. Nat. Chem. 2009, 1 (9), 729-732. https://doi.org/10.1038/nchem.416.

(10) Engwerda, A. H. J.; Maassen, R.; Tinnemans, P.; Meekes, H.; Rutjes, F. P. J. T.; Vlieg, E. Attrition-Enhanced Deracemization of the Antimalaria Drug Mefloquine. Angew. Chem. Int. Ed. 2019, 58 (6), 1670-1673. https://doi.org/10.1002/anie.201811289.

(11) van der Meijden, M. W.; Leeman, M.; Gelens, E.; Noorduin, W. L.; Meekes, H.; van Enckevort, W. J. P.; Kaptein, B.; Vlieg, E.; Kellogg, R. M. Attrition-Enhanced Deracemization in the Synthesis of Clopidogrel - A Practical Application of a New Discovery. Org. Process Res. Dev. 2009, 13 (6), 1195-1198. https://doi.org/10.1021/op900243c. 
(12) Zhang, M.; Schuster, G. B. Photoracemization of Optically Active 1,1'-Binaphthyl Derivatives: Light-Initiated Conversion of Cholesteric to Compensated Nematic Liquid Crystals. J. Phys. Chem. 1992, 96 (7), 3063-3067. https://doi.org/10.1021/j100186a053.

(13) Solntsev, K. M.; Bartolo, E.-A.; Pan, G.; Muller, G.; Bommireddy, S.; Huppert, D.; Tolbert, L. M. Excited-State Proton Transfer in Chiral Environments: Photoracemization of BINOLs. Isr. J. Chem. 2009, 49 (2), 227-233. https://doi.org/10.1560/IJC.49.2.227.

(14) Flegel, M.; Lukeman, M.; Wan, P. Photochemistry of 1,1'-Bi-2-Naphthol (BINOL) ESIPT Is Responsible for Photoracemization and Photocyclization. Can. J. Chem. 2008, 86 (2), 161-169. https://doi.org/10.1139/v07-143.

(15) Maria, T. M. R.; Marins, F. A.; Costa, J. B. S.; Silva, M. R.; Carrilho, R. M. B.; Monteiro, C. J. P.; Pereira, M. M.; Eusébio, M. E. S. Solid State Investigation of BINOL and BINOL Derivatives: A Contribution to Enantioselective Symmetry Breaking by Crystallization. Thermochim. Acta 2017, 648, 32-43. https://doi.org/10.1016/j.tca.2016.12.008.

(16) Takahashi, M.; Ogasawara, K. An Expedient Route to Some Monoalkyl Ethers of Enantiomerically Pure Bi- $\beta$-Naphthol. Tetrahedron Asymmetry 1997, 8 (18), 3125-3130. https://doi.org/10.1016/S0957-4166(97)00398-4.

(17) Carrilho, R. M. B.; Abreu, A. R.; Petöcz, G.; Bayón, J. C.; Moreno, M. J. S. M.; Kollár, L.; Pereira, M. M. New Binaphthyl-Based C3-Symmetric Chiral Hemilabile Monophosphite Ligands: Synthesis and Characterization of Their Platinum Complexes. Chem. Lett. 2009, 38 (8), 844-845. https://doi.org/10.1246/cl.2009.844. 
(18) Coquerel, G. Preferential Crystallization. Top. Curr. Chem. 2007, 269, 1-51. https://doi.org/10.1007/128_2006_077.

(19) Dunitz, J. D.; Bernstein, J. Disappearing Polymorphs. Acc. Chem. Res. 1995, 28 (4), 193-200. https://doi.org/10.1021/ar00052a005.

(20) Bučar, D.-K.; Lancaster, R. W.; Bernstein, J. Disappearing Polymorphs Revisited. Angew. Chem. Int. Ed Engl. 2015, 54 (24), 6972-6993. https://doi.org/10.1002/anie.201410356.

(21) Cruz-Cabeza, A. J.; Bernstein, J. Conformational Polymorphism. Chem. Rev. 2014, 114 (4), 2170-2191. https://doi.org/10.1021/cr400249d.

(22) W. C. McCrone. Polymorphism. In Physics and Chemistry of the Organic Solid State; 1965; Vol. 2, pp 725-767.

(23) Henck, J.-O.; Bernstein, J.; Ellern, A.; Boese, R. Disappearing and Reappearing Polymorphs. The Benzocaine:Picric Acid System. J. Am. Chem. Soc. 2001, 123 (9), 1834-1841. https://doi.org/10.1021/ja002113o.

(24) Brandel, C.; Amharar, Y.; Rollinger, J. M.; Griesser, U. J.; Cartigny, Y.; Petit, S.; Coquerel, G. Impact of Molecular Flexibility on Double Polymorphism, Solid Solutions and Chiral Discrimination during Crystallization of Diprophylline Enantiomers. Mol. Pharm. 2013, 10 (10), 3850-3861. https://doi.org/10.1021/mp400308u.

(25) Davey, R. J.; Sadiq, G.; Back, K.; Wilkinson, L.; Seaton, C. C. The Isolation of a Metastable Conglomerate Using a Combined Computational and Controlled Crystallization Approach. Chem. Commun. 2012, 48 (14), 1976-1978. https://doi.org/10.1039/C1CC16173C. 
(26) Harfouche, L. C.; Brandel, C.; Cartigny, Y.; Ter Horst, J. H.; Coquerel, G.; Petit, S. Enabling Direct Preferential Crystallization in a Stable Racemic Compound System. Mol. Pharm. 2019. https://doi.org/10.1021/acs.molpharmaceut.9b00805.

(27) Belletti G.; Tortora C.; Mellema I. D.; Tinnemans P.; Meekes H.; Rutjes F. P. J. T.; Tsogoeva S. B.; Vlieg E.; private communication September 2019. 